\title{
POLIO VACCINATION;
}

AN ANALYSIS OF CULTURAL AND TRADITIONAL BARRIERS

1. PhD (Rural Sociology) Abdul Wali Khan University Mardan, Pakistan.

2. M.Phil (Sociology)

The University of Agriculture Peshawar, Pakistan.

3. PhD (Sociology \& Post Doctorate) The University of Agriculture Peshawar, Pakistan.

4. DVM, PhD (Medicine) Abdul Wali Khan University Mardan, Pakistan.

5. PhD (Micro Biology) Center for Advanced studies in Vaccinology \& Biotechnology (CASVAB)

University of Balochistan, Quetta, Pakistan.

6. M.Phil (Sociology)

Shaheed Benizeer Bhutto University Dir (U), Pakistan.

Correspondence Address:

Ahmad Ali

Abdul Wali Khan University Mardan, Pakistan.

ahmadalia@awkum.edu.pk

dr.ahmadaup@gmail.com

Article received on:

13/07/2017

Accepted for publication:

$25 / 11 / 2017$

Received after proof reading:

02/01/2018

\section{INTRODUCTION}

Polio is a viral disease and the virus belongs to picornavirdae family with three major serotypes as PV1, PV2 and PV3 respectively. Immunity against all these three types is indispensible for prevention and control. ${ }^{1}$ The virus is usually transmitted through oral discharge and gets multiplied in the oral larynx and small intestine upon entry into human body. It attacks local lymphoid tissues and then enters blood system, while attacking on nervous system. Upon entering and spending 3-5 days in human, it could be isolated in the blood, feces and throat and could continuously discharged in stool for several weeks after infection. ${ }^{1}$ Pakistan had done remarkable job in containment of polio, still the recurrence and spontaneous occurrence could be the outcome of poor vaccination, substandard vaccines and inappropriate immunization. ${ }^{2}$
Extended programme of immunization (EPI) have been launched throughout Pakistan for babies and infant vaccination against different diseases including Polio. But due to some constrains its success rate is $54 \%$, despite concrete efforts to vaccinate each and every kid in the country. ${ }^{3}$ Pakistan spread over a terrain of glaciers, mountains and dispersed population size in the valley of Punjab and Baluchistan. And a huge population size of almost 180 million require huge money and energy to cope with such a challenging situation in teams of providing services with median schooling period for women with 10 and 3 years in urban and rural areas respectively.4-6 Polio is an endemic disease, spreading across the globe. Major factor was the immunization drive, which resulted in a comprehensive reduction from almost $6,00,000$ to 1,000 polio cases by $2000 .^{7}$ 
The effects of community interventions with respect to rate of uptake of polio vaccination through community mobilization efforts in northern Nigeria. It was found that in high risk communities people had low uptake of polio vaccination along with some other routine activities as supplemental vaccination. Misconceptions over polio vaccination in community and little trust in vaccine effectiveness for eradication of polio was some of the major causes. Similarly, Physicians and Pediatricians in Uttar Pradesh and Behar, India found that children with age group 1-5 had higher vulnerability to polio infection. They conceded with unawareness on part of parents regarding polio vaccination as an important barrier to polio eradication. Moreover, consistent immunization was identified as the most effective tool towards eradication of polio. ${ }^{9}$

Global Emergency Action Plan ${ }^{10}$ assessment of different strategies disclosed that polio like other diseases is both curable and preventable. Keeping in view these negative effects of polio, the world leading entities (WHO) in 1988 showed their agreement for the complete eradication of polio from the globe. The most polio cases surfaced in Muslim majority areas, which explored the major barriers for complete eradication of polio as religious and cultural influences over the people. Misconceptions and myths which negatively affected the child ammonization in Calabar, Nigeria. Data collected revealed that respondents were of the old thinking like, sacrificing of animals in rivers at midnight. Moreover, most of the care givers had the opinion that multiple vaccination could lead to harming the children. ${ }^{11}$

\section{RESEARCH METHODOLOGY}

A total of 200 respondents were selected from 364 households population of the area as per Sekaran $^{12}$ formula. A conceptual framework based on cultural barriers to polio vaccination (dependent variable) and impediments to polio vaccination (dependent variable) was worked out. For collecting primary data a well thought out and comprehensive interview schedule was designed, encompassing all the essential aspects of the study. The Interview Schedule was pre-tested for its relevance to objectives of the study and the inconsistencies and ambiguities were corrected before actual data collection. A simple frequency and Chi Square test Statistics were applied to study the association between independent variables using SPSS software. The procedure to calculate chi-square test statistics was outlined by Tai. ${ }^{13}$

\section{RESULTS AND DISCUSSIONS}

\section{Frequency and percentage distribution of cultural and traditional barriers to polio vaccination}

Culture and tradition of a society is the totality of its shared beliefs, norms, values, rituals, language and social character. Rural culture and traditions, though, rich in disseminating the folk heritage, but often considered hard to bringing changes into its own structural and functional fabrics.

Table-I indicated the cultural and traditional barriers to polio vaccination. Out of total $98.0 \%$ respondents disclosed that there was antivaccination concept (myth) in the community while $2.0 \%$ disagreed with the statement. Being traditional in nature, local community often had contain myth over the polio vaccination, these could be social cultural never religion, these findings were in support to Khan and Qazi ${ }^{14}$ reported that misconceptions about the nature of polio drops, and religious misinterpretations in masses and religious leaders, are the major obstacles in the real success of polio vaccination campaign. Regarding another statement that community response is positive to polio vaccination, $10.5 \%$ said Yes and majority i.e. $87.0 \%$ respondents had not agree to it, moreover 2.5\% responded in Uncertainty. These findings were in negation Mehmood $^{15}$ argued that response of community was positive towards polio vaccination. The new born polio affected in traditional way rather going for polio vaccination Majority i.e. $98.5 \%$ respondents were agreed while $1.5 \%$ respondents disagreed with this statement. It could be attributed to the prevalent traditional ways of treating the siblings. It usually expresses the spiritual and local quackeries, providing treatment from herbs. ${ }^{15}$ Out of total a 
majority i.e. $93.0 \%$ of the respondents pointed out that People thought polio vaccine affected the immune system of their children in negative way and $6.5 \%$ responded against this statement while $0.5 \%$ were uncertain about it. These results were in consonance to Paul ${ }^{16}$ who reported that the parents of children fear from side effects of polio vaccines. Rumors associating oral polio vaccine (OPV) with fears of cancer, HIV and sterility occasionally flare causing sporadic cases of vaccine refusals and polio outbreaks. ${ }^{17}$ In response to the statement that People hide their children during polio vaccination campaign due to fear from terrorists, $20.0 \%$ respondents were in agreement and $37.5 \%$ were against it while, $42.5 \%$ were uncertain about the statement.it could due to fear of insecurity as outlined by Khan and Qazi ${ }^{14}$ found that polio campaign was stopped in FATA due to security reason almost over 300,000 unvaccinated children in only Waziristan where the militants had banned vaccination in mid-2012. Similarly, $97.5 \%$ respondents believed that polio vaccine had side effects and $2.0 \%$ were disagree while $0.5 \%$ respondents had no idea about it. Almost $4.0 \%$ respondents of the locality admitted that polio is a fatal disease and majority i.e. $77.5 \%$ of the respondents contradicted the statement

\begin{tabular}{|c|c|c|c|c|}
\hline Cultural and traditional barriers & Yes & No & Uncertain & Total \\
\hline $\begin{array}{l}\text { The people treat the new born polio affected in traditional } \\
\text { way rather going for polio vaccination. }\end{array}$ & 197 (98.5) & $3(1.5)$ & 0 & $200(100.0)$ \\
\hline $\begin{array}{l}\text { People hide their children during polio vaccination cam- } \\
\text { paign in your area due to fear from terrorists }\end{array}$ & $40(20.0)$ & 75 (37.5) & 85 (42.5) & $200(100.0)$ \\
\hline $\begin{array}{l}\text { Community believes that polio vaccines has side effects } \\
\text { and thus avoid vaccinating offspring. }\end{array}$ & 195 (97.5) & $4(2.0)$ & $1(.5)$ & $200(100.0)$ \\
\hline
\end{tabular}

Table-I. Frequency and percentage distribution between cultural and traditional barriers

Association between cultural and traditional barriers with impediments to polio vaccination.

Table-II indicated relationship between any anti while, $18.5 \%$ respondents were dubious to it. In addition Out of total, $95.0 \%$ respondents reported that People considered polio vaccine as against their social and moral values and $5.0 \%$ respondents declined the statement.it could be due to the prevalent myths regarding polio vaccination Etokidem and Wondifon ${ }^{11}$ also found that local myths and misconceptions are the major barriers in polio eradication. They reported in their study that their respondents were of view that vaccines may cause many harmful side effects like illnesses, infertility and even death. Similarly, Abdulraheem ${ }^{18}$ had also found that the major reason for incomplete immunization among Nigerian rural children was parental belief in contrast to vaccination drive. In outbreak in Syria world report 2013 it was presented that misplaced beliefs about vaccine safety and the motives of vaccine campaigns have led to high rates of vaccine refusal. Some religious groups or ethnic groups show reluctance or resistance to vaccination because of some beliefs or misinformation which may result in low vaccine coverage. Moreover polio vaccination is considered against their social and moral values. ${ }^{9,16}$

vaccination concept (myth) in the community during polio vaccination campaign and impediments to polio vaccination was found significant $(p<0.05)$. It is obvious from these 
findings that owness to a program in a community has high success rate while dislikeness leads it otherwise as reported by Khan and Qazi ${ }^{14}$ that misconceptions about the nature of polio drops, and religious misinterpretations in masses and religious leaders, are the major obstacles in the real success of vaccination campaign. Similarly, the relationship between positive response of the community to polio vaccination and impediments to polio vaccination was found non-significant. Mehmood, ${ }^{19}$ argued that response of community was positive towards polio vaccination. In

\section{Attributes}

Any anti vaccination concept (myth) is present in the community during polio vaccination campaign in your area.

Community response is positive to polio vaccination in this area.

The people treat the newborn polio affected in traditional way rather going for polio vaccination.

People think that polio vaccine effect the immune system of their children in negative way.

People hide their children during polio vaccination campaign in your area due fear from terrorists.

Community believes that polio vaccine has side effects and thus avoid vaccinating offspring.

People consider polio vaccine is a fatal disease in your area.

People consider polio vaccine is against their social and moral values. addition to relation of new born polio affected traditional treatment with impediments to polio vaccination was found non-significant $(p>0.05)$ if vaccination drive is inefficient, certainly lead to non-vaccination to newly born babies. However, relationship between polio vaccine affect the immune system of the children in negative way with impediments to polio vaccination was found non-significant $(p>0.05)$. These findings were similar to Paul ${ }^{16}$ who reported that the parents of children fear from side effects of polio vaccines.

\section{Dependent variables}

Statistics

Impediments to polio vaccination

$\chi^{2}=6.803(0.019)$

Impediments to polio vaccination

$\chi^{2}=3.409(0.182)$

Impediments to polio vaccination

$\chi^{2}=1.827(0.242)$

Impediments to polio vaccination

$\chi^{2}=1.685(0.431)$

Impediments to polio vaccination

$\chi^{2}=10.14(0.006)$

Impediments to polio vaccination

$\chi^{2}=.867(0.648)$

Impediments to polio vaccination

$\chi^{2}=5.359(0.069)$

Impediments to polio vaccination

Table-II. Showing association between cultural and traditional barriers with Impediments to polio vaccination

Unlike the above relationship that people hide their children during polio vaccination campaign in the area due to fear from terrorists with impediments to polio vaccination was found significant $(p<0.05)$ as reported by Khan and Qazi ${ }^{14}$ who found that polio campaign was stopped in FATA due to security reason almost over 300,000 unvaccinated children in only Waziristan where the militants had banned vaccination in mid-2012. However, the relationship between the community belief that polio vaccine has side effects and thus avoid vaccinating offspring with impediments to polio vaccination was found non-significant $(p>0.05)$. Similar result were identified by ${ }^{17}$ that rumors associating oral polio vaccine (OPV) with fears of cancer, HIV and sterility occasionally flare causing sporadic cases of vaccine refusals and polio outbreaks. In addition, that People consider polio vaccine as a fatal disease with impediments to polio vaccination was found non-significant $(p>0.05)$. This disease and vaccination to decrease was comprehensively understood by the respondents in the study area, is depicted from this data. The relationship between People consider polio vaccine is against their social and moral values with impediments to polio vaccination was found non-significant $(p>0.05)$. These were due to non-consideration of local myths regarding polio vaccination. Local myths and misconceptions are the major barrier in polio eradication they reported in their study that their respondents were of view that vaccines may cause many harmful side effects like illnesses, infertility and even death. ${ }^{11}$ 


\section{CONCLUSIONS}

This study concluded that the existing culture was indebted with certain mysteries regarding the status of vaccination especially against polio. It was widely misunderstood to be leading to infertility and destroying the immune system with a number of side effects. Most of the people treat their polio affected children through traditional methods, despite proper and eminent efficient system of polio vaccination exists in the study area. Coordination between various state and non-state agents was comprehensively lacking. Support from clergy and other regional religious institutions should be taken into account for successful polio vaccination campaign. This will act as catalyst in removing the fears, misconceptions, and myths and other fabricated stories from the minds of local population.

Copyright@ 25 Nov, 2017.

\section{REFERENCES}

1. Atkinson W, Wolfe CJ, Hamborsky, and Mclntyre L. Poliomyelitis, Epidemiology and prevention of vaccine-preventable diseases. 11th ed. Washington DC: Public Health Foundation; 2009;231-243.

2. Bennett S, Woods T, Liyanage WM, Smith DL. A simplified general method for cluster-sample surveys of health in developing countries. World Health Stat Q. 1991.1; 44 (3):98-106.

3. Ali SZ. Health for all in Pakistan: achievements, strategies and challenges.

4. Bhore JC. Report of the health survey and development committee vol. III.

5. Mantey P. Polio Eradication Makes Progress in Africa. A Newsletter from the Office of Sustainable Development-SD Bureau for Africa, USAID SD Developments, Summer 2001.

6. Dietz VJ, Baughman AL, Dini EF, Stevenson JM, Pierce BK, Hersey JC. Vaccination practices, policies, and management factors associated with high vaccination coverage levels in Georgia public clinics. Archives of pediatrics \& adolescent medicine. 2000.1; 154 (2):184-9

7. Nathanson N, Kew OM. From emergence to eradication: the epidemiology of poliomyelitis deconstructed. American journal of epidemiology.
2010.

8. Nasiru SG, Aliyu GG, Gasasira A, Aliyu MH, Zubair M, Mandawari SU, Waziri H, Nasidi A, El-Kamary SS. Breaking community barriers to polio vaccination in Northern Nigeria: the impact of a grass roots mobilization campaign (Majigi). Pathogens and global health. 2012. 1; 106 (3):166-71.

9. Thacker N, Choudhury P, Gargano LM, Weiss PS, Pazol K, Bahl S, Jafari HS, Arora M, Dubey AP, Vashishtha VM, Agarwal R. Comparison of attitudes about polio, polio immunization, and barriers to polio eradication between primary health center physicians and private pediatricians in India. International Journal of Infectious Diseases. 2012. 30; 16 (6):e417-23.

10. Global Emergency Action Plan. Barriers to eradicating Polio in the Muslim World and the role of The Uk diaspora communities 2012.

11. Etokidem AJ, Ndifon W. Myths and misconceptions as barriers to uptake of immunization services in Nigeria. J Vaccines Vaccination. 2013; 4 (7): 204.

12. Sekaran, U. Research methods for Business. USA, Hermitage Publishing Services 2003.

13. Tai SW. Social science statistics, its elements and applications. Goodyear Pub. Co.; 1978.

14. Khan T, Qazi J. Hurdles to the global antipolio campaign in Pakistan: an outline of the current status and future prospects to achieve a polio free world. Journal of epidemiology and community health. 2013. 1; 67 (8): 696-702.

15. Kazi AM, Khalid M, Kazi AN. Failure of polio eradication from Pakistan: Threat to world health. J Pioneer Med Sci. 2014; 4 (1):8-9S.

16. Paul Y. Why polio has not been eradicated in India despite many remedial interventions? Vaccine. 2009. 8; 27 (28): 3700-3.

17. Bego A. Polio vaccine crisis, not peculiar to Nigeria WHO Director. The Daily Trust; (2003).

18. Abdulraheem IS, Onajole AT, Jimoh AA, Oladipo AR. Reasons for incomplete vaccination and factors for missed opportunities among rural Nigerian children. Journal of Public Health and Epidemiology. 2011. 30; 3 (4):194-203.

19. Mehmood K, Qadir HI, Rashid AZ, Bashir RA, Khosa ZA, Khalid S and Hashmi K 2014. Journal PMI. 26 (01): $48-54$. 
We know who we are, but do not know what we can be.

\section{- William Shakespeare -}

\section{AUTHORSHIP AND CONTRIBUTION DECLARATION}

\begin{tabular}{|c|c|c|c|}
\hline Sr. \# & Author-s Full Name & Contribution to the paper & Author $=$ s Signature \\
\hline 1 & Ahmad Ali & Researcher & \\
\hline 2 & Liaqat Ali & Data collection & \\
\hline 3 & Mussawar Shah & Proof reading & \\
\hline 4 & Naimatullah Khan & $\begin{array}{l}\text { Data collection and medical } \\
\text { support }\end{array}$ & \\
\hline 5 & Muhammad Shafee & Coordination & \\
\hline 6 & Sameerul Khaliq Jan & Data base for analysis & \\
\hline
\end{tabular}

